\title{
LA FORMULACIÓN DEL CRIOLLISMO EN JUAN JOSÉ DE EGUIARA Y EGUREN
}

\author{
Claudia COMES PEÑA \\ Universidad de Alicante
}

Un elemento que caracteriza un amplio sector de la producción literaria del siglo XVIII en Nueva España es la plasmación de un sentimiento criollista, una constante que vertebra multitud de obras adquiriendo su formulación definitiva como sistema de identidad cultural. La Bibliotheca Mexicana de Juan José de Eguiara y Eguren y, en especial, los prólogos o «Anteloquia» que la preceden es uno de los ejemplos más representativos de este fenómeno. Su obra no fue la primera en articularse bajo los presupuestos de la defensa del criollismo. La peculiaridad de esta obra y su mayor valor reside en que supo recoger, sintetizar y exponer por primera vez de forma sistemática estas ideas que estaban fermentando en la sociedad criolla novohispana.

La proximidad temporal de la aparición del criollismo con el proceso de independencia, y la concordancia que los estudios tradicionales han querido ver entre los presupuestos ideológicos de ambos procesos, han hecho que se haya establecido una relación de causalidad entre ambos, convirtiendo al criollismo en un sentimiento nacionalista que ya contenía los elementos que habrían de llevar a la comunidad novohispana hacia la independencia.

En este trabajo pretendemos analizar los rasgos que conformaban el sistema de identidad cultural criolla a partir del ejemplo de la obra fundamental de Juan José de Eguiara y Eguren que ya hemos citado y, a partir de esos datos, podremos dilucidar qué papel desempeñó el criollismo en el entramado social novohispano y hasta qué punto se le puede considerar como germen propiciador y responsable de la emancipación mexicana. 


\section{LA UNIVERSIDAD, CENTRO DE FORMACIÓN CRIOLLA}

La función que la universidad desempeñó en el desarrollo y sistematización de una conciencia de identidad criolla es un aspecto fundamental para la comprensión del fenómeno. Esta relación vino determinada por varios factores relativos a la organización de la sociedad novohispana y sus relaciones con la Metrópoli, así como por los ataques recibidos desde Europa.

La fundación de la Real y Pontificia Universidad de México surgió como respuesta a la necesidad de formación superior de las primeras generaciones que llegaron muy jóvenes o que nacieron en suelo americano. Este hecho ya nos da una pista de su importancia dentro de este movimiento cultural. Los españoles que venían de la península a ocupar cargos en la administración llegaban con una formación académica realizada. Los que estudiaban en esta universidad eran, precisamente, jóvenes pertenecientes a las clases criollas más altas. Fueron ellos mismos los que se convertirían más tarde en profesores y catedráticos, incluso en rectores, como fue el caso de Eguiara y Eguren. En el siglo XVIII era una institución que en todos sus escalafones estaba formada casi exclusivamente por criollos.

El hecho de que la élite criolla compartiera una formación académica común fue un factor determinante a la hora del nacimiento de esa identidad cultural y explica que ésta tuviera unos rasgos definitorios tan uniformes y compactos. La conciencia criolla adquiere así una unidad de criterio científico y humanístico que, rápidamente, les coloca frente a los españoles que llegaban a América, entrando aquí en juego otro factor que potencia las posturas criollas en la sociedad novohispana. Tal como ha sabido ver Ángel Rama (1995, p. 32), el aparato de poder estaba compuesto por una clase letrada con una fuerte conciencia de grupo y una escasa permeabilidad. La mayoría de los altos cargos estaban ocupados por personas que provenían de la península y los criollos sólo tenían acceso, salvo raras excepciones que también se dieron, a los puestos de menor entidad. La universidad y la formación que en ella recibieron los criollos, se convirtió en un arma para denunciar aquella discriminación. Si todos los españoles, tanto peninsulares como indianos, eran jurídicamente iguales, los cargos debían adjudicarse a las personas que demostraran una mayor preparación y los criollos pusieron todos los medios a su alcance para brillar en los estudios superiores. Pese a ello, la administración central siguió marginándolos de los órganos superiores de poder. Así, dentro de las luchas por la preeminencia entre criollos y peninsulares, la universidad se convierte en el único bastión claramente dominado por los primeros:

De esta suerte [...] crecerá la comunidad intelectual, la cual estará más unida debido [...] a la fuerza que adquieren los criollos en las instituciones enseñantes y en los claustros, en los que llegan a dominar casi por 
completo, y a su favorable posición social y económica. (Torre Villar 1993, p. 137)

La universidad de México se convierte en todo este proceso de formación de la identidad criolla en el centro de elaboración intelectual y de irradiación de la misma. Se trata, eso sí, del criollismo de las clases altas, de las élites que pretenden asumir el poder de la colonia. En ningún caso se puede identificar este proceso con el que se dará en las comunidades indígenas o en los estratos criollos socialmente inferiores. La universidad era un centro muy restringido y los criollos que aquí nos ocupan proyectaban en ella su idea social clara y fuertemente jerárquica.

Este elitismo, que en gran parte es trasunto de lo que ocurría en las universidades peninsulares, vino marcado desde sus inicios por la llegada de los jesuitas a Nueva España en 1572. Su presencia no fue requerida para desempeñar las tareas de evangelización (cosa que también hicieron) sino que les fue encomendada explícitamente la tarea de educar a los nacidos allí que vivían en la ociosidad y la opulencia. Es decir, desde un primer momento los jesuitas estuvieron ligados a la élite de los criollos. Fueron ellos los que se encargaron de aglutinar ese espíritu de grupo desde la cátedra universitaria. Una prueba muy clara del grado de implicación de los jesuitas en la formación de la identidad criolla la tenemos en la segunda mitad del siglo. Después de su expulsión, los jesuitas exiliados escribieron un gran número de obras en las que explicaban y defendían el mundo que les habían obligado a abandonar.

En la obra de Eguiara y Eguren se ven claramente reflejados todos estos rasgos. Él representa el punto en que culminan y se conforman las ideas criollas y el grupo que le rodea está formado en su mayoría por jesuitas. Con ellos mantiene estrecha relación y le ayudan en la confección de su Bibliotheca. El ejemplo más claro es su gran amigo Vicente López, autor del Dialogus Aprilis, obra en la que también se enaltece a los criollos y que se editó junto a la Bibliotheca. Este jesuita, pese a haber nacido en la España peninsular, inmerso en el mundo académico de la universidad mexicana, se identificó rápidamente con las reivindicaciones criollas y con su ideario cultural.

En la obra de Eguiara la universidad adquiere además una relevancia especial por otro motivo. Frente a los ataques de incultura y barbarie de que es objeto su tierra, él la enarbola como la prueba más fehaciente de la talla intelectual de México. En el prólogo VIII se dedica a enumerar los centros docentes mexicanos y presta una especial atención a la Real y Pontificia de su ciudad natal. Y hay más. El primer artículo de la Bibliotheca lo dedica precisamente a la universidad de México. En él traza su historia y la cubre de alabanzas situándola como centro irradiador de toda la cultura novohispana. 
Sin embargo, otra obra suya es quizá más representativa a este respecto. Nos referimos a su Selectae Dissertationes Mexicanae ${ }^{1}$, una obra teológica destinada a la enseñanza universitaria. Lo que primero llama la atención es el adjetivo «Mexicanae» en el título de una obra de teología general que no trata ningún aspecto específicamente relacionado con México. Se trata, sin duda, de resaltar el origen geográfico de la obra. Esto se corrobora cuando vemos que también añade el adjetivo a su propio nombre: «Su autor es D. Juan José de Eguiara y Eguren, mexicano» (\{1746\}1993,p. 55). Su función es la de hacer público que en México se estudia y que los mexicanos también dominan las severiores disciplinae. Pero más significativo aún del carácter vindicativo de la cultura mexicana que subyace a toda la obra es el prólogo que la antecede. En él no hace una introducción a los temas que va a tratar en el cuerpo del libro, sino que dedica la obra a la propia universidad y redacta una loa en su favor. Ensalza, a veces incluso en tonos hiperbólicos, la brillantez de sus profesores y alumnos en todas las materias y la sitúa como Minerva y alma mater de todo lo bueno que se ha pensado y escrito en Nueva España:

[...]cuantos escritores egregios, academias sapientísimas, hayas producido, de aquí puede conjeturarse fácilmente, porque, habiendo reunido hasta hoy en un repertorio casi dos mil autores de la América Septentrional, mientras preparo una Biblioteca Mexicana, y aguardando el día de reunir otros, [...] al revisar las bibliotecas y archivos y al escudriñar otros monumentos de este género, lo cual comencé desde hace un trienio, de ellos vindicarás para ti la mayor parte. (Eguiara y Eguren [1746]1993, p. 55)

La universidad funcionó, por tanto, como aglutinadora de las élites cultas criollas y como estandarte de su elevado nivel intelectual. En ella se dio forma al ideario de identidad cultural criolla y desde ella se reclamó el espacio de poder que, por derecho propio, debía corresponder a sus miembros.

\section{EL JUEGO DE FUERZAS ENTRE CRIOLLOS Y PENINSULARES}

De lo que hemos expuesto hasta ahora se puede ya percibir cómo el grupo criollo se definió en gran medida por oposición a los peninsulares y cómo la estructura social que la política metropolitana propició en Nueva España fue una de sus causas. Para la España peninsular, el imperio americano había constituido desde sus inicios un área de expansión y la mayor fuente de riquezas y materias primas. Se la había tratado siempre como un territorio dependiente y secundario.

El primer volumen de esta obra apareció publicado en 1746. Los manuscritos de los dos siguientes, debido a los problemas que suponia imprimir en México, fueron enviados a la península, pero se perdieron y nunca llegaron a ver la luz. 
Los cargos de mayor prestigio (que también eran los que mayores rentas proporcionaban) acababan siempre en manos de peninsulares y los criollos veían en ello uno de sus mayores agravios. Desde el punto de vista del español americano, esto constituye la causa del mal gobierno de las Indias: los recién llegados no conocen ni la tierra que deben gobernar, ni sus costumbres, ni sus leyes y ven la estancia en el Nuevo Mundo como algo provisional que les permitirá amasar una fortuna. En estas denuncias están implícitos los argumentos que esgrimirán ante el rey para reclamar una cuota de poder que ellos consideran legítima ${ }^{2}$. La constitución de una identidad criolla, la descripción de una serie de rasgos que les caracterizan como grupo, se ajusta perfectamente a este plan político. Mostrar las diferencias que este continente tiene respecto a la Metrópoli y el conocimiento que ellos tienen de él les sitúa en una posición privilegiada para poder ejercer directamente ese gobierno. Estas reclamaciones son sistemáticamente desatendidas, y el desequilibrio entre formación y poder social frente al escaso poder político al que tienen acceso provoca un fuerte malestar y una franca oposición a los peninsulares allí afincados.

La idea de que en este fenómeno se estaban dando ya las bases de las reclamaciones independentistas debe ser muy matizada. En el criollismo de esta época no hay un afán de independencia por un motivo bien claro: se forman como grupo para hacer frente al peso de los españoles en los órganos de poder. Los criollos no quieren eliminar esos órganos creados por la Metrópoli, sino ocuparlos ellos, ya que constituyen un entramado muy elaborado y asentado que les conviene conservar. De la Metrópoli venían los sueldos y la ventaja de contar con la legitimación tradicional de un sistema jerárquico que, si exceptuamos lo tocante a la prioridad para ocupar cargos, les favorecía enormemente.

En los «Anteloquia» de Eguiara las quejas hacia la Metrópoli se centran en los aspectos tocantes a la cultura. Nuestro mexicano ve en la distancia que separa los dos continentes el problema que dificulta en mayor medida la comunicación intelectual entre ambos y el propio desarrollo novohispano. Cuando en el prólogo $\mathrm{X}$ ensalza la calidad y cantidad de las bibliotecas que se esparcen por tierras americanas, pone de relieve el mayor mérito que tienen por lo costoso que resulta traer hasta allí los libros:

A fuerza de dinero conseguimos, no obstante, cuantos libros habemos menester, pues movidos los libreros y comerciantes europeos del incentivo del lucro, traen a estas tierras numerosas cajas de selectos volúmenes, que nos permiten recibir cada día los insignes y riquísimos tesoros de la sabiduría

Aunque un poco posteriores en el tiempo, hay dos textos recogidos por Dorothy Tranck de Estrada que son una perfecta muestra de que las quejas de los criollos se centraban en la marginación administrativa que sufrían, mientras que la legitimidad del poder del rey sobre Nueva España permanecía incuestionable. Uno de ellos lleva el significativo título de «Representación de la Universidad de México a Carlos III sobre la política de empleos» (Tranck de Estrada 1985, pp. 61-74). 
europea y poseer ejemplares muy poco corrientes. (Eguiara y Eguren [1755] 1986, p. 101)

Donde sí se muestra muy quejoso es en lo referente a las imprentas americanas que, debido a los gastos de importación, encarecen tanto el coste final de la edición de un libro que no todos los autores pueden permitirse publicar sus obras. Y ésta, y no el poco ingenio de sus habitantes, es la causa de que se editen tan pocos libros en América:

Ya se ven las causas de por qué tantas obras notables, elaboradas en nuestra América, yacen ocultas por los rincones de las bibliotecas o han perecido horadadas y corroídas por la polilla. (Eguiara y Eguren [1755] 1986, p. 139)

Escudándose de nuevo en las dificultades provocadas por la lejanía, critica el poco eco que tienen las obras americanas en España y el poco reconocimiento oficial que reciben de la Península:

Que si bien nuestro Católico Monarca y su Consejo de Indias colma de honores y recompensas a nuestros hombres beneméritos, así que los conocen, sólo tardíamente, en fuerza de la gran distancia, llega hasta la corte la noticia de sus obras y merecimientos. (Eguiara y Eguren [1755] 1986, p. 132)

De lo que más se duele Eguiara respecto a la Metrópoli y, en general, respecto al Viejo Continente, es del desconocimiento que allí tienen de los avances de la cultura novohispana y los ataques injustificados que ello provoca. Esta es la causa que le empuja a escribir su obra. La Bibliotheca Mexicana es, por principio y fundamentalmente, una réplica a lo que un español metropolitano y fuertemente europeísta, Manuel Martí, deán de Alicante, escribió acerca de México en su Epistolarum Libri Duodecim.

Los criollos, influidos por los modelos de trabajo de la Ilustración borbónica e incluso impelidos por la política de la Corona, emprenden la tarea de componer informes en los que, de forma crítica y sistemática, se reflejaba esa realidad americana sobre la que los reformadores querían actuar. Este estudio de la realidad adquirió en América unas connotaciones muy particulares. A partir de estos trabajos se hacen patentes las peculiaridades que diferencian el entorno novohispano del peninsular. Y no sólo la diferencia, también el valor de lo propio empieza a dejarse traslucir en la mentalidad de los que tenían aquella como patria de origen ${ }^{3}$. Un ejemplo de este fenómeno lo tenemos en la «Aprobación» que el marqués de Altamira escribió para el Theatro Americano ${ }^{4}$ de Antonio Villaseñor y Sánchez.

3 Recordemos que en esta época aún se consideraba «patria» como el lugar, ciudad o región, donde uno había nacido, es decir, lo que hoy consideramos como «patria chica», pero en ningún caso hacía referencia a la nación o estado al que uno pertenecía. (Almarza 1985).

4 Es muy significativo que esta obra se editara en 1746 , el mismo año en el que también fueron publicadas la Selectae Dissertationes Mexicanas de Eguiara y Eguren, de cuyo tono y finalidad de reivindicación criolla ya hemos hablado. 
En ella insiste, significativamente, en el valor que la obra tiene como estímulo para que los criollos estudien su entorno y respondan así con argumentos sólidos a las calumnias europeas ${ }^{5}$ sobre el atraso americano, además de beneficiar con sus resultados, y esto es importante, al Rey, a la Iglesia, a la patria y al bien público. Según podemos comprobar en los textos de la época, el pensamiento ilustrado sí influyó en el nacimiento de una identidad cultural criolla en tanto que impulsaba el conocimiento de lo propio y promovía la crítica de los problemas y las deficiencias de la región, pero lo hacía siempre desde el propio entramado administrativo y oficial, desde dentro del poder mismo. No debemos olvidar que el respeto y adhesión a la monarquía era, junto a los dogmas católicos y el sistema escolástico, uno de los límites infranqueables de la Ilustración oficial tanto en la península como en Nueva España.

Esta identificación entre identidad criolla y sentimiento independentista se dará sólo en la frontera con la centuria siguiente como elaboración que podríamos llamar a posteriori para justificar de manera socio-cultural una actitud que nacía de intereses y con objetivos muy distintos a los que perseguían los intelectuales criollos que aquí nos ocupan:

Es cierto que parece existir un vacío entre ese pensamiento ilustrado tan adherido aún a los cimientos del régimen colonial y tan partícipe del sentimiento nacional hispánico. Pero no es necesario esperar una transición explícita hacia una Ilustración antihispana e independentista, dado que el movimiento de independencia surgió, salvo casos excepcionales, como un brusco aunque titubeante proceso impulsado por las crisis de las monarquías ibéricas y la presión inglesa. (Chiaramonte 1974, p. XXI)

Las palabras de Chiaramonte son muy esclarecedoras $y$, a nuestro entender, dan en la clave de la relación entre el sentimiento de identidad cultural criolla y la independencia mexicana en relación al poder metropolitano ${ }^{6}$. Sólo cuando ese poder central flaquea y deja de significar estabilidad para los criollos surge la idea de la independencia. Ante la amenaza de un vacío de poder y el peligro que eso siempre significa para las clases acomodadas de un país, en una confluencia de intereses de distintos ámbitos, ven los criollos en la independencia la posibilidad de llenar ese vacío. La elaboración teórica revolucionaria se puso en marcha sólo cuando el proceso empezó a verse claro y para ello recurrieron a una síntesis de lo que se había configurado como rasgos definitorios de la cultura criolla en oposición a la española y de los modelos revolucionarios ilustrados que ya se habían utilizado en Europa.

Como ejemplo de esas calumnias pone, al igual que Eguiara y Eguren, la epístola del deán Martí que se menciona y rebate en los prólogos a la Bibliotheca Mexicana.

Preferimos este planteamiento al establecido por Torre Villar: «Es justo en la primera mitad del siglo XVIII que los novohispanos advierten ser miembros de una comunidad en la cual se dan las características que configuran una nación, la cual debe culminar convirtiéndose en un estado, en entidad jurídica capaz de organizarse y gobernarse a sí misma.» (1993, p. 156). 


\section{EL CRIOLLISMO Y SU FORMULACIÓN COMO RÉPLICA}

La idea que de América se venía dando en España, y en general en Europa, se centraba en la superabundancia de riquezas y materias primas, un aspecto que tuvo múltiples desarrollos. América se instaura como naturaleza pura, como tierra, fauna y flora con el grado de hostilidad hacia el hombre que ello implica. Esta magnificación de un sólo aspecto del Nuevo Continente hacía que la labor humana quedara, o bien en la penumbra, o bien estigmatizada por la Leyenda Negra, creando la idea de un espacio sin letras. Fue un proceso complejo y muchas veces propiciado por el mismo poder central que no quería perder lo que hasta entonces había sido su fuente de ingresos y su mercado más importante? ${ }^{7}$ Una de las bases que justificaba la presencia y el dominio español en América, junto a la evangelización, era la idea de que los nuevos territorios eran inferiores y por ello necesitaban del gobierno español. Para asentar esta idea se recurrió a la teoría de los climas y su influencia en los hombres que Jean Bodin había rescatado de los autores clásicos ${ }^{8}$.

En la formulación de Bodin, se relacionaba el temperamento de los hombres con el clima en que vivían y de ello se derivaba el tipo de gobierno que mejor se les ajustaba. Esta teoría se propagó rápidamente y fue utilizada interesadamente para justificar la inferioridad americana. Igual que Bodin, francés, había adjudicado a su país el más beneficioso de los climas, así todos los que recurrieron a esta teoría se adjudicaron también el más propicio de los climas, asignando a las demás regiones climas que generaban un peor desarrollo tanto físico como intelectual del hombre En España esto también ocurrió, pero lo curioso es que aplicaron el peor de los climas a sus propias colonias. Todos los americanos, tanto indígenas como criollos, se convertían en seres inferiores que necesitaban del gobierno superior de la Metrópoli. Este es uno de los aspectos contra los que los criollos más violentamente reaccionan y Eguiara también lo hace desde sus «Anteloquia»:

Juan de la Puente no vaciló en publicar que el cielo americano influye inconstancia, lascivia y mentira, envilecedoras características de los indios y

Según afirma Jovellanos en su Informe dado a la junta de Comercio y Moneda sobre el embarque de paños extranjeros para nuestras colonias, «las colonias en tanto son útiles en cuanto ofrecen un seguro consumo al sobrante de la industria de la metrópoli, y esta cosa no es otra cosa que lo que resta del consumo interior». (Gil Amate 1998, p. 25).

8 Jean Bodin publicó en 1576 los Seis libros de la República, una obra de teoría política que pretendía sentar las bases universales del derecho público Dentro de esa pretensión de universalismo y consciente de la diversidad humana a la que debía hacer frente, dedica el primer capítulo del libro quinto a los «Procedimientos para adaptar la forma de república a la diversidad de los hombres y el modo de conocer el natural de los pueblos», desarrollando aquí la teoría de influencia climática a la que hacemos referencia. En su obra, sin embargo, no hace ninguna referencia especial a América. Su escala climática se basaba en la división según los paralelos terrestres, por lo que se correspondían las mismas afirmaciones para los dos lados del Atlántico. 
españoles nacidos en las Indias occidentales, así como en declarar que el suelo de América es más apto para producir plantas y minas que para engendrar hombres, pues estos, al igual que las mejores semillas pierden gradualmente por culpa de la tierra en que se echa sus cualidades innatas, se han apartado y degenerado de las buenas costumbres de sus progenitores hispanos. ([1755] 1986, p. 181)

Nuestro mexicano no sólo tacha de ingenuas estas afirmaciones y le acusa sutilmente de estar llamando lascivos a obispos de la Iglesia católica y a gobernantes designados por el rey, sino que retoma él mismo la teoría de los climas y la invierte totalmente. El clima americano, lejos de ser perjudicial para el intelecto, se convierte en uno de los factores que determinan el gran ingenio y afición a las letras de los americanos:

D. Juan de Cárdenas [...] tiene por evidente y fuera de toda duda que los españoles nacidos en América sobresalen por su ingenio agudo, delicado y vivo, explicando largamente las causas naturales de este hecho. [...] y al igual que otros autores, atribuyen a la naturaleza del clima, del sol y del suelo americanos, no sólo la mayor vivacidad e ingenio de los naturales de estas partes, sino también el hecho de que los nacidos en otros países se hagan más dispuestos e ingeniosos cuando habitan las regiones mexicanas. ([1755] 1986, p. 104)

La idea que de estas réplicas se desprende está íntimamente ligada con la formación de la conciencia criolla. En las críticas españolas ya hemos atisbado la intención marginadora que las alimentaba. Es la Metrópoli la primera en agruparlos como clase, como grupo, al apartarlos sistemáticamente de ciertos sectores por el mero hecho de haber nacido en América. La reacción lógica es la de modificar esa situación demostrando su valía y analizando las causas que les hacen diferentes conformando así la creación de una identidad propia, un imaginario cultural diferenciado. Este sentimiento de marginación y menosprecio les coloca en la necesidad de crear una historia social, cultural y espiritual paralela a la oficial en la que ellos tomen el poder de la palabra y se describan a sí mismos operando una reelaboración de la historia americana desde un nuevo punto de vista.

Con este trasfondo aparecen los textos en los que se plasma el ideario de identidad cultural criolla: nacen como réplica a otros textos que ellos consideran injuriosos. Frente a la verdad oficial ellos escriben otra verdad sobre la realidad americana. El desarrollo de una conciencia criolla se puede detectar a partir de la ausencia o presencia de réplicas a las obras en las que los autores europeos ponían en duda la capacidad intelectual americana, o directamente los situaban en un plano claramente inferior. En las dos centurias anteriores las réplicas escaseaban y cuando aparecían lo hacían de forma aislada'. Sin embargo, lo que ocurre en el

9 Por ejemplo, León Pinelo escribe su Hypomnema Apologeticum en respuesta a las afirmaciones que sobre América realizó Justo Lipsio en la obra titulada Lovanium, en la cual el belga hablaba de la ausencia de instituciones docentes en el Perú. 
siglo XVIII es bien diferente. No es sólo Eguiara y Eguren el que reacciona violentamente contra el deán alicantino, sino que podemos encontrar toda una pléyade de réplicas ${ }^{10}$ directas a Manuel Martí en las que se rebaten sus ideas y ensalzan el mérito intelectual mexicano y la necesidad de que ellos mismos den a conocer sus talentos para demostrar la falsedad de estas acusaciones. Poco o nada había cambiado en el tono y contenido de esos ataques. Lo que sí se había transformado era la actitud de los criollos ante ellos. Ahora, en torno a esos ataques, empezarán a perfilar las bases que caracterizarán y definirán su identidad cultural.

Si consideramos la Bibliotheca Mexicana y en especial sus Anteloquia como la primera formulación sistemática de la identidad criolla, comprobamos que su planteamiento mismo tiene como eje fundamental la réplica. Si Manuel Martí acusaba de bárbaros a los indios y de desinteresados por la cultura a los criollos, Eguiara dedica sus prólogos a demostrar el alto grado de civilidad de los indios y la fecundidad de las letras de los criollos. Además, hace la réplica de forma explícita. El título del primer prólogo ya lo demuestra: «Con objetivo de divulgar la causa determinante de este escrito, tráese a colación la carta 16 del libro 7, incluida por el deán de Alicante Manuel Martí en el tomo dos de sus Epístolas» ([1755] 1986, p. 49). Y líneas más abajo declara que la finalidad del libro es «aniquilar, detener, aplastar y convertir en aire y humo la calumnia levantada a nuestra nación por el deán alicantino» ([1755] 1986, p. 54). Las interpelaciones al deán a los largo de los prólogos son tan abundantes que no podemos reproducirlas aquí todas. Baste una como ejemplo del lenguaje vehemente y lleno de indignación que utiliza para referirse a Martí:

¿Con qué derecho se les borra [a los españoles americanos], pues, de la lista de los hombres cultos, se les moteja de vivir en la soledad e ignorancia más espantosa de las letras, y se los presenta tan bárbaros, salvajes y aborrecedores de la cultura? [...] Quedando así de manifiesto la enorme injusticia que cometen los que les consideran como bestias [a los indios], y el absoluto desconocimiento, así de las antigüedades mexicanas, como de los historiadores europeos más famosos y conspicuos que demuestra el deán alicantino en sus duros ataques a los indios. ([1755] 1986, pp. 81-82)

No hace falta mucho más para convencernos de la importancia que tuvo el carácter de réplica en esta obra, tal como ocurrirá con los demás litigantes que hacen mención del alicantino. Los rasgos que los mismos criollos ven como propios y donde demuestran su valía se dibujan exactamente en torno a los puntos principales de las críticas que menosprecian su mundo y su cultura. La réplica de Eguiara y Eguren a Martí es uno de los casos que mejor ilustran esta relación

13 Hasta ahora hemos recopilado nada menos que once textos pertenecientes a esta polémica y que geográficamente exceden el territorio mexicano, habiéndose encontrado réplicas desde Quito y Cuba. 
directa entre los ataques al Nuevo Mundo y la forma que adquirió la identidad cultural criolla novohispana.

\section{LA ELABORACIÓN DE UNA IDENTIDAD CULTURAL CRIOLLA}

No sólo el contenido, también la forma que da Eguiara y Eguren a su alegato criollista nos aporta información sobre su finalidad. La Bibliotheca Mexicana recoge una pequeña biografía y la producción bibliográfica de los autores que han escrito en suelo novohispano. Este tipo de obras recopilatorias se suelen dar siempre asociadas a momentos históricos en los que una determinada comunidad cultural siente la necesidad de mostrar, o más bien demostrar, el grado de madurez que ha alcanzado su tradición literaria ${ }^{11}$. La obra de Eguiara supone dar a conocer y elevar el rango intelectual de su tierra frente a los ataques europeos que se habían producido, según él, por desconocimiento. Como dice, la obra de Eguiara no era sólo «un catálogo de libros, una serie de vidas ejemplares, sino la expresión de una obra cultural y espiritual en la que se mostraban sus múltiples raíces, el significado de cada una de ellas, el producto de esa conjunción y el valor de sus frutos» (1986, p. CCXXVIII). Y son precisamente esas raíces y su significado lo que ahora vamos a ver, tal como lo elabora en los «Anteloquia» hasta convertirlo en la expresión de una identidad cultural novohispana.

\section{La raíz indígena}

La gran novedad que Eguiara y Eguren introduce en el pensamiento novohispano es la de incorporar el mundo cultural indígena como una de las bases constitutivas del ser criollo, es decir, lo introduce dentro de la línea histórica de los mexicanos entendidos como una continuidad. Esta operación responde principalmente a dos hechos. Por una parte, Manuel Martí había introducido a los indios como una de las causas de la barbarie americana. Eguiara lo rebatirá demostrando el alto nivel cultural y de civilización que habían tenido los aztecas, la grandeza de su imperio. Por otro lado, proclamará a los criollos herederos directos de esa grandeza, con lo que se adjudican una raigambre cultural y social no sólo antigua sino también elevada que, como ya veremos, pone al mismo nivel que el pasado antiguo de la cultura europea. Un claro ejemplo de esto lo observamos en el tratamiento que hace de la ciudad de México. Ya desde las Cartas de Relación de Hernán Cortés se la identificó con Roma, con la cuna de un imperio;

1I Lo mismo había ocurrido con uno de los modelos que toma Eguiara y Eguren para componer su obra, la Bibliotheca Hispana de Nicolás Antonio, en la que su autor declara escribirla para enaltecer las glorias de su patria y probar que España tenía una cultura propia producto de su espíritu. 
se la llamó la gran ciudad y sus habitantes fueron descritos como nobles, cultos y ricos. Eguiara, como tantos otros, identifica plenamente aquella ciudad, pese a que fue destruida, con la ciudad en la que él vive.

Sin embargo, no hay que llevar la defensa indigenista de Eguiara a extremos. Cuando él alaba la cultura indígena, lo hace respecto de la precortesiana. En ningún momento la identifica con la de los indios que en su época poblaban Nueva España. De hecho, cuando en el prólogo II inicia la descripción de las características y el nivel de la cultura indígena hace referencia explícita a que se trata de antigüedades mexicanas, a un ciclo cultural pasado, válido como antecedente pero no como modelo. Más aún, cuando más adelante, en el prólogo XIX, se refiere a los indígenas de su tiempo mide su grado de desarrollo en relación a las letras que han alcanzado en los estudios introducidos por los españoles, es decir, en la medida en que han europeizado sus conocimientos abandonando los antiguos modos.

La información que nos da sobre el mundo azteca se limita al plano cultural, como es lógico por el carácter de su obra. Para resaltar más el valor de la ilustración que poseían los indios a la llegada de los españoles, establece siempre comparaciones con el imaginario cultural europeo: su alfabeto es parecido al de los fenicios, sus códices se asemejan a las profecías caldeas; sus libros sagrados son como los calendarios sagrados cristianos; e incluso tenían libros de registro para nacimientos, muertes, matrimonios y archivos históricos que compara con los de Simancas. Después hace una enumeración y alabanza de las instituciones enseñantes que poseían y sus métodos, poniéndolas como antecedente de las universidades novohispanas. El elogio de la cultura indígena lo finaliza haciendo un repaso de todas las materias que cultivaron, haciendo especial hincapié en la poesía.

El conocimiento que demuestra nuestro autor sobre este tema tiene una base claramente bibliográfica y erudita. La gran cantidad de datos que nos aporta tienen como fuente obras de otros autores de las cuales nos cita los títulos. Los autores que utiliza como autoridades se pueden dividir en dos grupos claramente diferenciables que cumplen en la obra funciones distintas. Eguiara abunda en noticias recogidas de intelectuales extranjeros. En ellos busca los juicios imparciales y objetivos de los hechos de Indias. Sin embargo, la referencia última se la asigna siempre a escritores hispanos, especialmente a criollos, de los cuales nos ofrece una larga lista acompañada con las obras que tratan el tema. Con ello demuestra a Martí la abundancia de noticias que circulaban impresas sobre el antiguo México al tiempo que otorga a los criollos la última palabra en cuanto a su conocimiento: ellos son los que han conocido directamente el mundo indígena, los que han estado en contacto con él y, por lo tanto, los más autorizados para hablar de ello. 
Eguiara supo recoger toda la tradición de estudios sobre la cultura indígena realizados en Nueva España desde el siglo XVI y con ello demostrarle a Martí (y a los que pensaban como él) lo equivocado que estaba al motejarlos de bárbaros. Nuestro rector de la Universidad de México no sólo pretende destruir ese tópico, sino que pretende dar un cimiento de prestigio cultural a la civilización criolla de la que él se siente parte.

\section{La raíz española}

A partir del prólogo VIII Eguiara y Eguren comienza su defensa del desarrollo de la cultura de origen español en suelo novohispano. Si Manuel Martí decía que en aquellas tierras nadie sentía interés por aprender, dedicados como estaban a la acumulación de riquezas, Eguiara se encarga de demostrarle su error enumerando la lista de centros dedicados a las letras. La universidad, colegios y seminarios forman la infraestructura que ha permitido la aparición del enorme número de literatos que pueblan su patria. Como hizo en el caso de la cultura indígena, también nos habla de los libros que circulan entre ellos y de la abundancia de bibliotecas. En los prólogos XI, XII y XIII se detiene en la calumnia americana y alude a los tópicos que circulan en Europa referentes a la influencia del clima en su ingenio, tema al que ya hemos aludido antes, comentando ampliamente los dos artículos que Feijoo había escrito defendiendo a los americanos. Los últimos prólogos, como lo exigía el carácter de la obra, son un esbozo de lo que había sido el desarrollo de la literatura novohispana desde el descubrimiento hasta el tiempo en el que él escribe.

La raíz hispana de la cultura criolla determina un modelo muy concreto de intelectualidad. En México se estudia latín y teología, filosofía y derecho, se leen las revistas y libros europeos, sobre todo españoles. En pocas palabras, la cultura universitaria novohispana se configura como un calco de la española, tanto en instituciones como en resultados. Los criollos querían medirse en condición de igualdad con los peninsulares y para ello necesitan demostrar que dominan los mismos códigos. En este sentido hay que entender el hecho de que la obra fuera escrita en latín, la lengua de prestigio en Europa y la que el mismo Martí había utilizado en su epístola. También a ello se debe el grado de erudición y constantes citas de autoridades que recorren los «Anteloquia». Con todo ello Eguiara y Eguren busca uno de sus objetivos: demostrar que la cultura desarrollada en la Nueva España no tiene nada que envidiar, ni en grado ni en contenido, a la que cultivaban los españoles. 


\section{CULTURA DE SÍNTESIS}

Si a Eguiara y Eguren lo que le interesaba era simplemente demostrar el grado de desarrollo intelectual novohispano respecto del europeo, nos podemos preguntar por qué introduce también en su obra la cultura de los indígenas. La respuesta que inmediatamente nos aparece es pensar que lo hizo porque los indígenas formaban un colectivo al que Martí también atacó duramente denominándolos bárbaros y salvajes. Pero esto no nos parece suficiente para justificar el tono y la amplitud de su defensa. Ésta adquiere otra dimensión e incluso otra función si prestamos un poco de atención al método que utilizó para dicha defensa.

Desde el descubrimiento de América su población indígena, con sus culturas tan diferentes a la europea, se había convertido en el elemento diferenciador más importante de esta tierra. Además, el carácter evangelizador de la conquista creó un especial interés por conocer su mundo e impulsó el estudio de sus culturas por parte de los religiosos españoles. Este interés, representado paradigmáticamente por la obra de fray Bernardino de Sahagún, quedó truncado en el siglo XVII por la política de represión que emprendió la Metrópoli y que se extendió a las colonias $^{12}$. Pues bien, Eguiara rescata esa tradición americanista del renacimiento y la actualiza dándole un carácter y una función diferentes. El trato de Eguiara con ese mundo precolombino ya no es directo, como lo fue en el caso de aquellas otras obras que él cita, sino que se trata de un rescate operado a partir de los textos españoles que trataron el tema en los primeros tiempos de la conquista. Sobre ellos realiza una elaboración intelectual, una ordenación de elementos que da como resultado la eliminación de los cortes históricos entre las dos civilizaciones, la azteca y la colonial. Tal como lo plantea Eguiara, la historia cultural mexicana es un proceso continuado en el que la llegada española no supuso una ruptura, sino más bien una evolución. En palabras de Torre Villar, «en Eguiara se dará por primera vez en forma magistral y grandiosa, la idea de que la fusión de las dos culturas es lo que caracteriza y define la cultura mexicana» (1986, p. CCXXXVIII). Pero, a su vez, este hecho cumple un objetivo determinado dentro del programa de legitimación cultural criolla. La forma en que da a conocer el mundo indígena, es decir, a través de las obras de españoles afincados largo tiempo o nacidos en México, implica la idea de que los mismos indígenas no han sido capaces de mostrar al mundo esa cultura suya y que los europeos tampoco han sabido acercarse a ella. El criollo se convierte así en el intermediario cultural entre los dos mundos, el único capaz de entender y traducir ese universo al código cultural europeo. Los criollos ostentan, por tanto, el conocimiento de los dos códigos, el literario europeo y el de la cultura indígena, y eso les da un poder y una autoridad de la que carecen tanto los propios indígenas como los europeos.

12 Una excepción de importancia fue la obra de Carlos de Sigüenza y Góngora que Eguiara cita en diversas ocasiones. 
Dentro del pensamiento criollo, dentro de la elaboración de una identidad cultural propia, la Bibliotheca Mexicana significa su primera explicación y justificación amplia y sistemática. El surgimiento de esta corriente fue posible gracias a la confluencia de diferentes factores del ambiente social y cultural de la época que propiciaron la necesidad criolla de una réplica a los ataques recibidos desde Europa. Y es este carácter de réplica, a Manuel Martí en el caso que nos ocupa, lo que marca desde su inicio muchos de sus rasgos y, lo que es más importante, determina en gran manera la necesidad de incluir a los indios americanos dentro del área cultural que se defiende. Toda elaboración de un sistema de identidad cultural es una elaboración intelectual y Eguiara la realiza situando en un mismo plano dos procesos históricos separados temporal y culturalmente. Contra el ataque de Martí, pone a un mismo nivel el pasado, representado por la civilización azteca, y el presente, representado por los criollos, efectuando un juego sincrónico que superpone dos planos en una solución de continuidad logrando la visión de ambos periodos como parte de una sola realidad cultural.

Por todo ello, el valor de la Bibliotheca Mexicana como expresión de la mentalidad criolla es incuestionable. Supone el inicio de un pensamiento novohispano que se sabe y se quiere diferente del peninsular pero que no rechaza las aportaciones que la Metrópoli les ha legado y de las cuales ellos mismos forman parte. No hay que olvidar que estos criollos, pese a todos los problemas que tienen con España, en ningún momento han puesto en cuestión la institución monárquica y su carácter divino. Muy al contrario, precisamente se amparan en ella para sus reivindicaciones.

\section{REFERENCIAS BIBLIOGRÁFICAS}

ABELLÁN, José Luis. 1981. Historia crítica del pensamiento español. III. Del Barroco a la Ilustración, Madrid, Espasa-Calpe.

ALMARZA, Sara. 1984. "La frase nuestra América: historia y significado», Cahiers du Monde Hispanique et Lusobrasilien Caravelle, $\mathrm{n}^{\circ}$ 43, pp. 5-22.

- 1985. «Variaciones en la noción de patria en la época colonial», Cuadernos americanos, $\mathrm{n}^{\circ} 5$, sep.-oct., pp. 186-196.

BODIN, Jean. [1576] 1985. Los seis libros de la República, estudio preliminar y traducción de Pedro BRAVO GALA, Madrid, Tecnos.

CHIARAMONTE, José Carlos. 1979. Pensamiento de la Ilustración. Economía y sociedad iberoamericanas en el siglo XVIII, Caracas, Ayacucho.

- 1989. La Ilustración en el Río de la Plata, Buenos Aires, Puntosur Editores.

EGUIARA Y EGUREN, Juan José. [1746] 1993. «Prólogo a las Selectas Disertaciones Mexicanas» ed. y trad. de Roberto HEREDIA CORREA, en Ernesto 
de la TORRE VILLAR, Juan José de Eguiara y Eguren y la cultura mexicana, México, U.N.A.M., pp. 53-88.

- [1755] 1986. Biblioteca Mexicana, pról. y trad. de Benjamín FERNÁNDEZ DE VALENZUELA, estudio preliminar de Ernesto de la TORRE VILLAR, 5 vols., México, U.N.A.M.

FERNÁNDEZ VALENZUELA, Benjamín. 1986. «Prólogo», en Juan José de EGUIARA Y EGUREN, Biblioteca Mexicana, México, U.N.A.M., pp. IIIXLVIII.

GERBI, Antonello. 1945. «Diego de León Pinelo contra Justo Lipsio. Una de las primeras polémicas sobre el nuevo mundo», Fénix, $\mathbf{n}^{\circ} 2-3$, pp. 187-231 y 601-612.

GIL AMATE, Virginia. 1998. «De españoles a americanos: variantes del criollismo en el siglo XVIII», Arrabal, n 1 , pp. 23-38.

HIGGINS, Anthony. 1996. «La Biblioteca Mexicana: hacia una poética de la legitimidad criolla», Revista de Crítica Literaria Latinoamericana, $\mathrm{n}^{\circ} 22, \mathrm{pp}$. 77-87.

MILLARES CARLO, Agustín. 1944. Prólogos a la Biblioteca Mexicana de Juan José de Eguiara y Eguren, México, Fondo de Cultura Económica.

- 1986. Cuatro estudios biobibliográficos mexicanos, México, Fondo de Cultura Económica.

PÉREZ, Josehp. 1990. «La ilustración americana» en AA.VV., Coloquio Internacional Carlos III y su siglo. Actas, Madrid, Universidad Complutense, pp. 733-746.

RAMA, Ángel. 1995. La ciudad letrada, Montevideo, Arca.

ROVIRA SOLER, José Carlos. 1993-1994. «Para una revisión de la polémica mexicana dieciochesca con Manuel Martí, deán de Alicante», Sharq AlAndalus, $\mathrm{n}^{\circ}$ 10-11, pp. 607-636; y en Entre dos culturas. Voces de identidad hispanoamericana, Alicante, Universidad, 1995, pp. 45-62.

TORRE VILLAR, Ernesto de la. 1986. «Estudio preliminar» en Juan José de EGUIARA Y EGUREN, Biblioteca Mexicana, México, U.N.A.M., pp. XLIXCCCLIII.

- (coord.) 1993. Juan José de Eguiara y Eguren y la cultura mexicana, México, U.N.A.M.

- 1995. «Las culturas indígenas en algunos pensadores novohispanos», Hispania Sacra, 1995, pp. 97-108.

TRANCK DE ESTRADA, Dorothy. (ed.) 1985. La Ilustración y la educación en Nueva España, México, S.E.P. 